\title{
Mortar Consumption Characteristics of 'Brickwork' and a Framework for Managing Brick and Mortar Walls in Chaotic Environments
}

\begin{abstract}
Vasantha Abeysekera
Abstract: This study investigated how bricks and mortar could be used in a chaotic environment where brick and joints sizes could be varied to achieve better outcomes (such as cost minimisation) through an understanding of mortar consumption characteristics of brickwork. This was made possible by integrating three innovative concepts, viz. 'type' of wall, 'cost polarity', and ‘bricks to mortar' ratio.
\end{abstract}

New formulae for computing mortar volumes had to be developed as the simple formula of subtracting the volume of bricks from the volume of wall that did not produce accurate mortar volumes. Having validated these formulae, mortar volumes in different joints were computed. Accordingly, it was found that the bed-joint accounted for the largest portion of mortar in single brick thick walls in English bond, irrespective of the size of brick used. With more than two thirds of the total volume of mortar in the bed joint (even with a smaller bed joint of $10 \mathrm{~mm}$ ), it plays a significant role in changing the volume of mortar in brickwork.

As the volume of mortar in the study walls was as high as $73 \%$ when compared with (less than) $25 \%$ for walls with standard brick and joint sizes, the very notion of what 'brick-work' was challenged. This led to the identification of three 'types' of walls, namely, 'mortar-wall' (with volume of mortar over $50 \%$ ), 'brick-mortarwall' (with volumes of mortar between $25-50 \%$ ), and 'brick-wall' (with a volume less than $25 \%$ ) with corresponding 'bricks to mortar' ratios of less than 1, 1 to 3 , and greater than 3. This classification was used for specifying a 'type' of wall.

It was found that 'brick to mortar' ratio was quite sensitive to variations in small values of the bed joint when large bricks were used though this was not the case with smaller bricks and larger bed joints. This suggests the importance of controlling workmanship if the ratio is to be maintained at small values of bed joint. A strategy-map for selecting a desirable 'bricks to mortar ratio' was provided based on 'type' of wall, brick and joint sizes, and degree of control required for ensuring workmanship.

In order to make strategic decisions on costs, the concept of 'cost polarity' (cost of density of bricks to mortar) was used. Accordingly, a cost-efficient 'type' of wall could be selected based on whether cost polarity was less than 1 or greater, using a strategy-map for such decision making. Further savings in costs could be achieved by using the strategy-map for 'brick to mortar' ratios whilst giving consideration to the build ability of the bed joint, and sizes of other joints including joint fullness.

The framework thus proposed provides a fresh perspective on how walls built with bricks and mortar could be managed (particularly in Sri Lanka) with potential for enormous cost savings using a chaotic environment to bring a new order.

Keywords: $\quad$ brick size, brickwork, bed joint, chaos, cost polarity, chapparu, mortar

\section{Introduction}

Simply, brickwork consists of bricks and mortar. Indeed, it is these two materials that are used for building a wall in different proportions engaging various processes which

BSc Hons Civil Eng (First Class; UoM, SL), MSc (L'boro, UK), PhD (L'boro, UK), CEng, MIE(SL), MNZIQS, Director (Construction Management Studies), Faculty of Engineering and Surveying, University of Southern Queensland, Australia. 
vary globally including brick and joint sizes. Amidst this diversity one wonders, whether it would be possible to understand underlying features that may have a profound impact on how bricks and mortar could and should be used. For example, should more mortar or more bricks be used in the construction of walls? How do these characteristics vary with respect to different brick and joint sizes? Should bricks and joints be standardised? What impact would such changes have on time and cost?

The task of responding to such questions becomes even more challenging when such environments are chaotic as in Sri Lanka where there is an abundance of different sizes of bricks (Fig. 1) even within the same locality, as the main source of bricks is from a cottage industry with significantly large outputs [1]. Yet walls of a given (or standard width) could be built using an 'innovative' practice commonly referred to in Sri Lanka as 'Chapparu' (Fig. 2) bringing a degree of order to what may be referred to as 'chaoticbrickwork' or 'non-standard' brickwork[2] or as 'chapparu' brickwork [3], [4].
Interestingly, such practices make brickwork in Sri Lanka different to what is seen in the developed world. However, what is most interesting and rewarding about this 'chaotic' environment is that it provides a fertile ground for studying and understanding fundamental issues impacting on the management of brickwork - issues that have been taken for granted for generations often influenced by standardised practices adopted by countries that use factory produced bricks.

\section{Study Aims and Methodology}

\subsection{Aims and Objectives}

Given the above background, the main intention of this study is to understand the impact of brick and joint sizes (study variables) on 'mortar consumption' and thereby develop a framework or to recommend how bricks and mortar could be used in a chaotic environment.
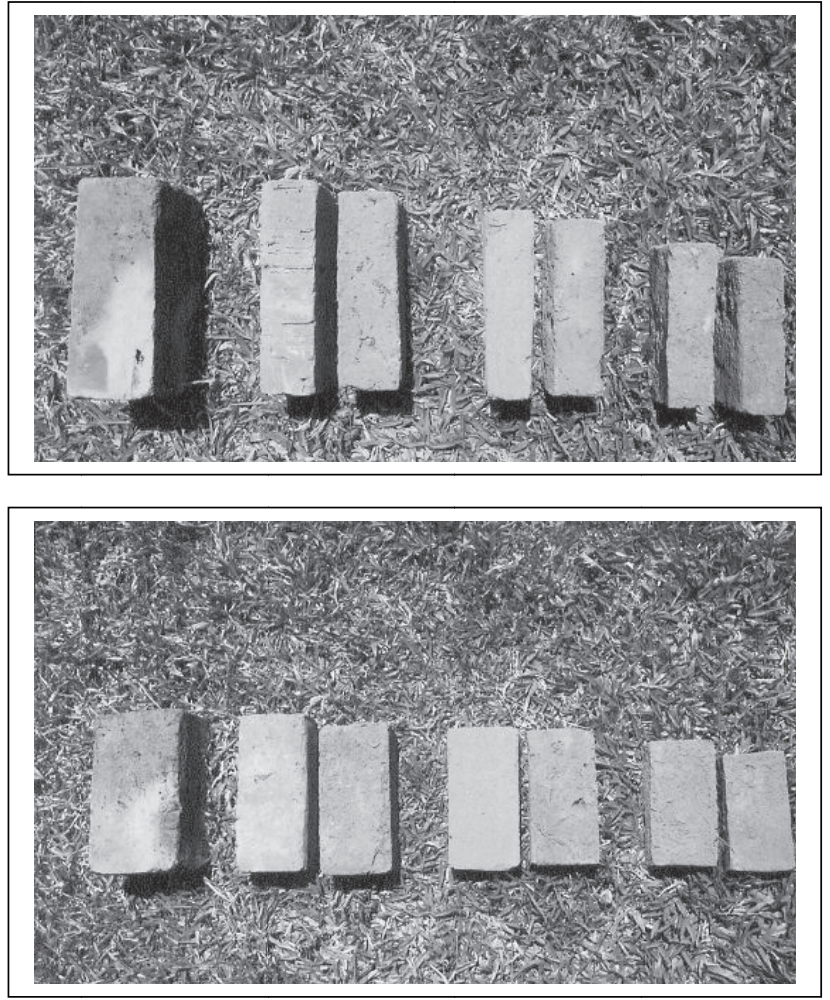

Figure 1 -Different sizes of non-standard bricks

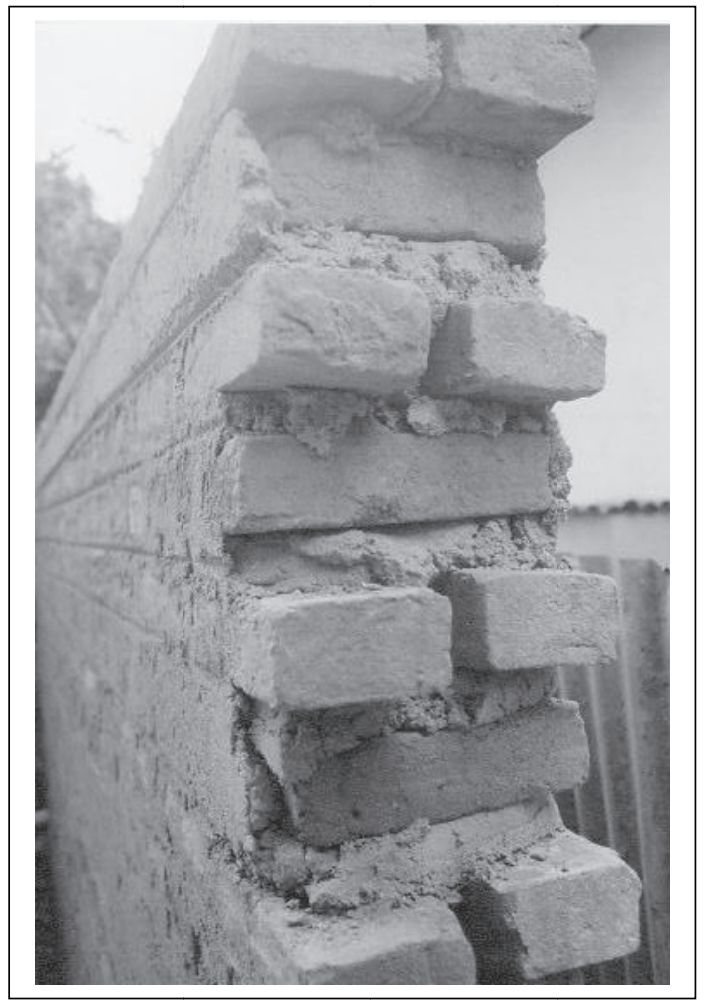

Figure 2 - A chaotic or non-standard brick wall with 'chapparu' (mortar on vertical surfaceof wall making it flat as a plate) 
A number of questions spring up as hinted before: What proportion of mortar is used in brickwork? To what extent does the volume of mortar vary with different sizes of bricks and joints? How sensitive are such variations to changes in mortar consumption? Should more mortar or bricks be used? What is the impact on time and cost of such changes? These are but a few questions that needs to be answered and the findings of this study is expected to provide a basis for such understanding.

\section{$2.2 \quad$ Methodology}

In order to make such decisions, firstly, it is necessary to find a way to assess the volume of mortar in brickwork. At first glance, this seems a mundane task: simply, subtract the volume of bricks from the volume of wall to arrive at the volume of mortar. However, a number of field studies showed that this simple equation does not lead to accurate volumes! As such, one of the fundamental investigations that had to be carried out was to ascertain why this was so and thereby arrive at an accurate method of predicting the volume of mortar with different sizes of brick and joints in order to ensure the validity and reliability of decisions on how bricks and mortar should be used.

Investigations revealed that inaccuracies could have stemmed from (a) how the average size of bricks used was established (b) the degree of fullness of brickwork joints (c) the basis on which theoretical volumes were compared (d) the degree of compaction of mortar due to static and dynamic loads, and (e) the type of formula used for calculating mortar volumes. These issues are discussed in the ensuing paragraphs.

\subsubsection{Computing brick dimensions and distortion factors}

Initially, bricks were measured using the 'bulk' approach recommended in SLS 39:1978 and BS 3921:1985 to arrive at the 'nominal' dimension of a stack of bricks wherein 24 bricks picked randomly were placed contiguously end to end lengthwise, side to side breadth-wise, and on edge with the total end to end distances divided by 24 to arrive at the average length, breadth, and height of bricks respectively. On reflection it was realised that this method of arriving at average dimensions could inflate the volume of bricks if there were irregularities in shape of the brick (say warping) and also due to any surface protrusions.

Sri Lankan bricks are produced predominantly by a cottage industry. As such, it was not surprising, that the average size so arrived could have been inaccurate due to deformations. This led to the development of a 'distortion factor' for each 'dimension' of the brick and also for the 'volume' of a brick by dividing the average 'bulk' dimension by the average 'unit' dimension with 'unit' dimensions being computed by measuring each dimension of the brick at the centre. Variation of the distortion factor for 'brick volume' so computed is shown in Fig. 3 with variations from $2-20 \%$ justifying the decision to measure brick by brick to arrive at the average than using 'bulk' measurements.

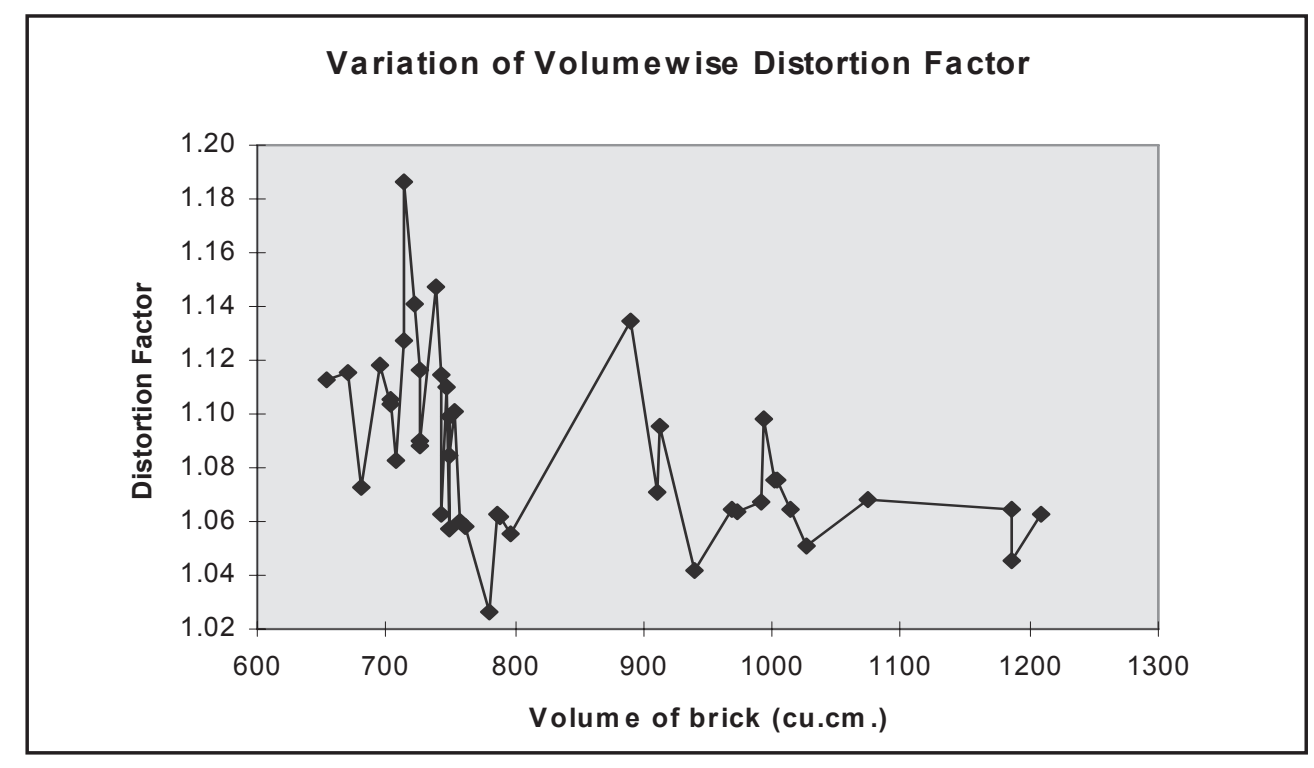

Figure 3 - Variation of volume-wise distortion factor 


\subsubsection{Establishing fullness of brickwork joints}

It is easy to reason out in retrospect why theoretical mortar volumes differ with field volumes due to the improper or under filling of brickwork joints. Perhaps, it is necessary to briefly describe how walls are built in Sri Lanka in order to understand why this is so.

The practice of making brickwork joints is different to those adopted in the UK although not entirely different to practices adopted in China. One main difference with the UK method is that bricks are not buttered on the edge before being laid on a course of brickwork. Instead (in Sri Lanka), all bricks are placed side by side on bed mortar irrespective of whether it is a stretcher or a header course with mortar placed on bricks spread across by a trowel allowing the mortar to fall into joints. Not always do bricklayers make a genuine attempt to shove mortar into the thin vertical joints using the trowel-edge in a motion that can be best described as 'chopping'. Moreover, Sri Lankan mortars are coarse and not buttery (as in the UK) making it difficult if not impossible to utilise the practice of buttering the brick with mortar before being placed. Furthermore, as brick dimensions are usually not dimensionally coordinated (in Sri Lanka), the 'chapparu' joint on the header course (see Fig. 4) is filled only after laying bricks on the stretcher course on top.

As such, five factors were established to accurately assess 'joint fullness' for each joint depicted in Fig. 4 which is described as a footnote to the figure. The degree to which these joints were filled was assessed visually with randomly selected walls on 59 sites.

The results given in Table 1 clearly justify the use of such factors as joints were not completely filled. It is seen that of all the joints, the 'wall joint' was the least filled with considerable variations as evidenced by the high standard deviations. Whilst the cross joints in both the header and the stretcher courses were seen to be filled more or less to the same extent, the chapparu, like the bed joint appears to be almost full all the time. It is worth noting that under-filled (or unfilled) vertical joints do not have an impact on strength although this practice may not be acceptable for other reasons such as sound insulation or rain penetration [5], [6].

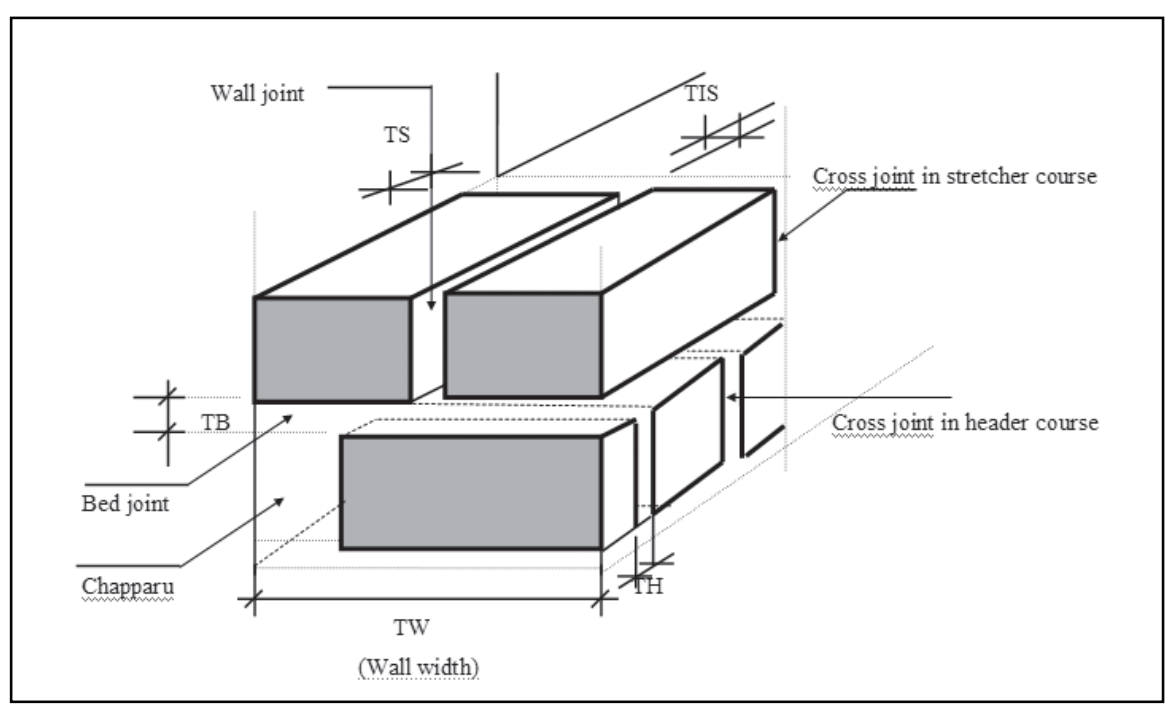

Figure 4 - Joint fullness factors in a 'representative unit' of brickwork for a

Type 2 chapparu wall in English Bond(Note: For a type 1 wall, chapparu will be on both sides of the h/c; fullness factors of joints:F1-bed joint, F2- chapparu, F3-h/c cross joint, F4- stretcher course cross joint, F5-wall joint; TB -thickness of bed joint sometimes referred to as bed mortar thickness or BMT; see Fig. 1 for a photo of this sketch) 
Table 1 - Joint fullness factors for study walls

\begin{tabular}{|l|c|c|c|c|}
\hline Joint type & Average & Std. Dev. & \multicolumn{2}{|c|}{ Range } \\
& & & Min. & Max. \\
\hline Bed joint (F1) & 1 & 0 & 1 & 1 \\
\hline Chapparu joint (F2) & 0.998 & 0.013 & 0.9 & 1 \\
\hline H/c. Cross joint (F3) & 0.842 & 0.156 & 0.15 & 1 \\
\hline S/c. Cross joint (F4) & 0.880 & 0.119 & 0.75 & 1 \\
\hline Wall Joint (F5) & 0.476 & 0.332 & 0.15 & 1 \\
\hline
\end{tabular}

Abbreviations: S/c- Stretcher course; H/c - Header course;

Study walls - 59 (one per site)

\subsubsection{Field volumes of mortar and proxy measures}

On the issue of how actual (field) volumes of mortar were measured, it is necessary to point out that original comparisons were made by using measured volumes of sand. This was obviously one source of error although it appeared that it was not an irrational approach given that it was a common practice for arriving at the mixed volume of concrete using the volume of coarse aggregate alone (i.e. metal) with the notion that cement and fine aggregate (sand) including water would fill the voids.

Perhaps, it is also useful to mention that the practice in Sri Lanka is to prepare mortar on site by mixing cement and sand as opposed to using ready-mixed cement-mortar. As such, one of the initial attempts (as noted before) was to measure the volume of sand assuming that it would be the same as the volume of mortar given that it would be an onerous task to measure mixed mortar without inconveniencing the workers. Indeed, it was easier to measure the volume of sand as gaugeboxes were used particularly in formal construction. As such, this approach was not rejected completely as it was convenient to do so and a factor was developed to convert dry volumes to mixed volumes, more as a way of using data already collected. However, as the study progressed, the actual volume of mortar used was measured (using gauge boxes) to improve accuracy whilst taking an effort to minimise disruptions to work.

\subsubsection{Assessing mortar compaction}

Yet another reason that was thought to account for variances in measured and theoretical volumes was the extent of compaction mortar is subjected to static and dynamic loads during the construction of a wall. This is not an easy task to assess as the degree of compaction cannot be judged visually unlike 'joint fullness' so there was a need to consider an approach by which compaction can be simulated. Thus the attempt was to consider different degrees of compaction so as to arrive at a 'value' that would minimise variances but in doing so it was thought appropriate to restrict the simulation to the bed joint only as it held the largest proportion of mortar of all joints in brickwork (discussed later), and was also the joint that was subjected to weight of brick courses.

In order to develop a methodology to simulate compaction, it was necessary to understand the extent to which mortar was compressible. This was achieved by filling a cylinder made from a PVC pipe $75 \mathrm{~mm}$ diameter and $30 \mathrm{~cm}$ in height. Thereafter mortar was filled in three stages with each stage compacted 25 times with a circular rod with a cross section of 2.5 sq.m. The compaction was calculated as follows:

Compaction Factor (COF)

='Compaction' / Height of loose mortar, where 'compaction' was measured as the distance from the top of the cylinder to the compacted surface, and height of loose mortar as the height of the cylinder.

The results are given in Table 2 showing that COF varies with type of sand (used for making mortar)with finer sands showing a higher level of compressibility. In fact, it can also be shown that there is a greater reduction in volume when fine or medium sands are used for preparing mortar indicating that it would be cost-effective to use coarse sand for building walls than fine or medium sand particularly if coarse sand is cheaper[1]. 
Table 2 - Variation of compaction factor (COF) with type of sand

\begin{tabular}{|c|c|c|c|c|}
\hline \multirow{2}{*}{} & \multirow{2}{*}{ Overall } & \multicolumn{3}{|c|}{ Type of Sand } \\
\cline { 3 - 5 } & & Coarse & Medium & Fine \\
\hline Average & 0.246 & 0.214 & 0.247 & 0.303 \\
\hline Std. Dev. & 0.047 & 0.027 & 0.039 & 0.044 \\
\hline Min & 0.164 & 0.164 & 0.197 & 0.223 \\
\hline Max & 0.350 & 0.241 & 0.350 & 0.350 \\
\hline No. of sites & 42 & 15 & 19 & 8 \\
\hline
\end{tabular}

It should be pointed out that $\mathrm{COF}$ is a measure of the maximum compaction. In reality, the actual compaction would not necessarily be at such values. Accordingly, it was necessary to introduce a factor labelled as the 'degree of compaction' (DOC) to simulate different levels of compaction for which purpose it was necessary to focus on the ratio of 'loose mortar to compacted mortar' which can be shown to be equal to ' $1 /(1-\mathrm{COF})$ '.In fact, the degree of compaction was taken as a percentage of this for calculation purposes as described later in section 3 .

\subsubsection{Methods for estimating field volumes of mortar}

Having understood some of the main reasons why theoretical volumes differ with measured field volumes and how these issues may be dealt with, it was necessary to develop a formula that would predict field volumes accurately so as to study the variations of mortar in brickwork joints with different sizes of bricks, joints, and wall widths.

Three methods were conceived for this purpose whilst reflecting on local conditions where joints were under-filled, brick bats were used (in order to minimise waste but resulting in more joints), and with different types of end conditions of walls (viz. returning walls, buttressing columns, etc.). In passing, it is worth noting that the impact brick-bats on the load carrying capacity of walls have been studied, and interestingly, it has an insignificant impact on strength [7].The methods developed are as follows:
i. $\quad$ Full Wall Method (FUM)
ii. Representative Unit Method (RUM)
iii. Course Based Method (COB)

In the FUM method, the wall is considered as a whole. The volume of bricks and openings are deducted to arrive at the 'theoretical' volume of mortar. This relationship can be shown as: Volume of Mortar $=$ Volume of Wall - Volume of Bricks - Volume of Openings

In the RUM method, a cuboid consisting of two bricks from each type of course, i.e. a header and a stretcher is selected. The cuboid (i.e. the representative unit)shown in Fig. 4 is used as the basis for computing the volume of mortar. The volume of mortar in each type of joint within this 'representative unit' (i.e. the cuboid) is computed multiplying the volumes so computed by the corresponding joint-fullness factors (see Fig. 4 for explanation of these factors). Thereafter, these volumes are aggregated to arrive at the total volume of mortar in the cuboid through which the volume of mortar used for a whole wall is extrapolated.

In contrast, in the COB method, the entire wall is treated as an aggregation of courses of brickwork. A course consists of a layer of bed mortar and a layer of bricks. The volume of mortar in the bed-joint is computed by deducting the volume of brick-courses (and not bricks) from the volume of the wall. Although the process of computing bed mortar appears straight-forward, the computation of the volume of mortar in other joints (such as wall-joints and cross-joints), require consideration of the arrangement of bricks within each course. Following are some of the reasons as to why this is necessary:

i. Use of brick-bats in both stretcher and header courses of varying numbers. (Brick-bats referred to herein consist mainly of three quarter bricks, half bricks, one third bricks and/or quarter bricks.)

ii. Not all courses are of equal length.

iii. End conditions of walls are different, for example the wall may be confined between two columns, connected to a returning wall at one end, or free at both ends

iv. To take account of openings left for scaffold putlogs or openings for windows.

The formulae developed for computation of mortar volumes are as shown below. Course 
type indicator (CTI) is taken as 0 for a stretcher course and 1 for a header course; the reasons are self-explanatory.

\begin{tabular}{|c|c|}
\hline In bed joints $=$ & $\begin{array}{l}\text { F1 } \times \text { [av. wall thickness } \times\{\text { (av. wall ht. } \times \text { av. wall } \\
\text { length }- \text { av. brick ht. } \times \Sigma(\text { eff. length of a course) }\}]\end{array}$ \\
\hline In wall joints $=$ & $\begin{array}{l}\text { F5 } \times[\Sigma\{(\text { av. wall thickness }-2 \times \text { av. breadth of a } \\
\text { brick) } \times \text { av. brick ht. } \times \text { (length of wall joints) }\}]\end{array}$ \\
\hline where, length of wall joints. $=$ & av. brick length $x$ eq. no. of bricks \\
\hline In 'chapparu' of header courses = & $\begin{array}{l}\text { F2 } \times[\Sigma\{(\text { av. wall thickness }- \text { av. brick length }) x \\
\text { eff.course length } \times \text { av. brick ht. }\}]\end{array}$ \\
\hline In cross joints of stretcher courses $=$ & $\begin{array}{l}\mathrm{F} 4 \mathrm{x}[\Sigma\{(\text { eff. course length-aggregate length of } \\
\text { bricks \& bats }) \mathrm{x} \text { av. brick ht. } \mathrm{x} \text { av. brick length } \mathrm{x} \\
(1-\mathrm{CTI})\}]\end{array}$ \\
\hline In cross joints of header courses $=$ & $\begin{array}{l}\text { F3x [\{(eff.course length - aggregate breadth of } \\
\text { bricks \& bats) } x \text { av.brick ht. } x \text { av. wall thickness } x \\
(1-C T I)]\end{array}$ \\
\hline
\end{tabular}

It must be pointed out that care needs to be exercised when computing 'effective course length' particularly to the end conditions of the walls built. For example, if the wall is built between two columns as against building a free standing wall with a returning wall to be built later, the calculation of effective course length' should reflect whether the end joints contain mortar or not. A comparison of these methods is given in Table 3. It is seen that, the COB method would be the best despite a higher degree of difficulty in estimating mortar volumes, with RUM next, and FUM being the worst.

\section{Formulae Development and Validation}

The above mentioned formulae need data for prediction and these include measurement of brick and joint sizes amongst other measures. With $\mathrm{COB}$, it will be necessary to measure number of brick-bats used on a course by course basis counting full bricks, three-quarter bricks, half bricks, one-third size bricks and quarter bricks. The end conditions need to be accounted as well.

A total of 20 walls were studied with one wall per site whilst measuring the volume of mortar in each case in order to compare theoretical volumes as predicted by formulae with the measured field volumes. Results are shown in Table 4.

Table 3 - A Comparison of Methods for Computing Mortar Volumes

\begin{tabular}{|l|c|c|c|}
\hline \multicolumn{1}{|c|}{ Feature } & \multicolumn{3}{c|}{ Method } \\
\hline SPECIFICS:Ability to account for ... & FUM & RUM & COB \\
\hline Use of brick-bats & Average & Poor & Good \\
\hline Openings & Good & Good & Good \\
\hline Different end constraints of walls & Good & Poor & Good \\
\hline Joint fullness and compaction & Poor & Good & Good \\
\hline IN GENERAL: Ability to ... & \multicolumn{3}{|c|}{} \\
\hline Account for site conditions & Average & Average & Good \\
\hline Estimate mortar volumes accurately & Average & Average & Good \\
\hline Estimate volume of mortar in walls & Average & Good & Cumbersome \\
\hline Estimate volume of mortar in joints & Poor & Good & Cumbersome \\
\hline
\end{tabular}

Interpretation aid: Poor - Method cannot take account of 'features' listed in the first column;

Average - Possible with some modifications;

Cumbersome - Method can account but process of doing so takes time. 
Table 4 - Variance of RUM, FUM\&COB volumes with measured volumes of mortar (\%)

\begin{tabular}{|c|c|c|c|}
\hline Method & RUM & FUM & $\mathrm{COB}$ \\
\hline Average & -9.174 & -8.290 & -4.967 \\
\hline Std. Deviation & 4.600 & 4.699 & 4.175 \\
\hline $\begin{array}{ll}\text { Range : } & \text { Maximum } \\
& \text { Minimum }\end{array}$ & $\begin{array}{c}-3.163 \\
-19.6124\end{array}$ & $\begin{array}{c}0.670 \\
-18.113\end{array}$ & $\begin{array}{r}-0.769 \\
-14.926\end{array}$ \\
\hline
\end{tabular}

According to these results, $\mathrm{COB}$ volumes are mostly less than the field volumes and were the closest to field volumes with the smallest standard deviation as well. These results confirm the assertions made in Table 2 particularly regarding the accuracy of the $\mathrm{COB}$ method. However, in order to improve the accuracy of these formulae further, it was seen necessary to simulate compaction related issues to account for the reduction in volume due to compaction (as described in section in 2.3.3). Accordingly, it was possible to introduce a hybrid factor labelled as the "joint fullness and compaction factor (JFC) by incorporating the compaction factor $(\mathrm{COF})$ and joint fullness factors as follows:

$\mathrm{JFC}=$ Joint Fullness Factor $\mathrm{x}[1+\{\mathrm{DOC} /(1-$ $\mathrm{COF})\}]$

Of the five types of joints, as mentioned before, the joint most likely to undergo compaction is the bed joint, which incidentally is the joint which contains the largest volume of mortar (shown later). The procedure adopted was to compute RUM and COB volumes again, using five DOC factors of $5 \%, 10 \%, 15 \%, 20 \%$ and $25 \%$. As before, the volume of mortar predicted by these methods were compared with field volumes. The results of this exercise are shown in Table 5

The values in Table 5 show that as the degree of compaction increases from $5 \%$ to $25 \%$ average-variance decreases (from being negative to zero) and continue to increase positively thereafter. The degree of compaction (DOC) which gives a zero average variance for COB volume was interpolated be equal to $10.456 \%$. The corresponding figure for RUM volume was $11.725 \%$. These values are logical in that the compaction due to static and dynamic pressures is at the lower end as expected when compared with a maximum of $100 \%$. Accordingly, it is reasonable to use the JFC factors given in Table 6 for multiplying values for F1 (Joint fullness factor for bed mortar) when using RUM or COB methods.

Table 5- Variance of 'method' volumes with varying degrees of bed mortar compaction

\begin{tabular}{|c|c|c|c|c|c|c|}
\hline DOC (\%) & 0 & 5 & 10 & 15 & 20 & 25 \\
\hline $\mathrm{JF}(=\mathrm{F} 1)$ & 1 & 1 & 1 & 1 & 1 & 1 \\
\hline JF on bed mortar & 1 & $1+\frac{0.05}{(1-\mathrm{COF})}$ & $1+\underline{0.1}$ & $1+\frac{0.15}{(1-\mathrm{COF})}$ & $1+\frac{0.2}{(1-\mathrm{COF})}$ & $1+\frac{0.25}{(1-\mathrm{COF})}$ \\
\hline Formula: & RUM & RUM & RUM & RUM & RUM & RUM \\
\hline Average $(\%)$ & -9.37 & -5.37 & -1.38 & 2.62 & 6.62 & 10.62 \\
\hline Std.Dev(\%) & 4.60 & 4.74 & 4.91 & 5.10 & 5.31 & 5.55 \\
\hline $\begin{array}{ll}\text { Range }(\%) & \text { Max } \\
& \text { Min }\end{array}$ & $\begin{array}{r}-3.16 \\
-19.61\end{array}$ & $\begin{array}{r}1.07 \\
-15.05\end{array}$ & $\begin{array}{r}5.65 \\
-11.71\end{array}$ & $\begin{array}{r}10.25 \\
-8.48\end{array}$ & $\begin{array}{r}14.86 \\
-5.24\end{array}$ & $\begin{array}{l}19.47 \\
-2.01\end{array}$ \\
\hline Formula: & $\mathrm{COB}$ & $\mathrm{COB}$ & $\mathrm{COB}$ & $\mathrm{COB}$ & $\mathrm{COB}$ & $\mathrm{COB}$ \\
\hline Average $(\%)$ & -8.56 & -4.57 & -0.57 & 3.43 & 7.42 & 11.42 \\
\hline Std. Dev (\%) & 4.70 & 4.86 & 5.06 & 5.27 & 5.50 & 5.76 \\
\hline $\begin{array}{ll}\text { Range(\%) } & \text { Max } \\
& \text { Min } \\
\end{array}$ & $\begin{array}{r}0.67 \\
-18.11 \\
\end{array}$ & $\begin{array}{r}5.28 \\
-13.56 \\
\end{array}$ & $\begin{array}{r}9.89 \\
-9.26 \\
\end{array}$ & $\begin{array}{r}14.50 \\
-6.02 \\
\end{array}$ & $\begin{array}{r}19.11 \\
-2.79 \\
\end{array}$ & $\begin{array}{r}23.72 \\
0.45 \\
\end{array}$ \\
\hline DOC (\%) & 0 & 5 & 10 & 15 & 20 & 25 \\
\hline
\end{tabular}

Note: All sites have been taken into computations (59 walls in 54 sites).

Hence the marginal difference in values related to zero DOC. 
Table 6 - Multiplying factor for Joint Fullness factor for bed mortar (F1)

\begin{tabular}{|r|c|c|}
\hline Method & RUM & COB \\
\hline Multiplying factor & $1+\underline{0.11725}$ & $1+\underline{0.10455}$ \\
& $(1-\mathrm{COF})$ & $(1-\mathrm{COF})$ \\
\hline
\end{tabular}

It must be pointed out that both the RUM \& $\mathrm{COB}$ methods give access to the concept of compaction easily in contrast with FUM although the latter could also be modified to account for compaction. However, as it cannot be used accurately for predicting joint volumes, its use has not been discussed.

For the purpose of validating the formulae so developed, a validation exercise was undertaken on three construction sites and the results are given in Table 7 . It is clear from these results that variances are reasonably low $(<6 \%)$. However, it may be necessary to increase the number of sites for further validation particularly with mortars using different types of sand although there is no reason to doubt the reliability and the validity of the procedure adopted.

\section{Mortar Volumes in Brickwork}

The discussion hitherto has been on understanding why theoretical predictions have been different to field volumes. Reasons have been established and formulae refined to improve accuracy to a high degree as explained hitherto. As such, the purpose of this section is to understand the impact of changes in brick and joint sizes with respect to mortar usage using the computational methods developed before.

Table 7 - Results of validation studies for mortar consumption methods

\begin{tabular}{|c|c|c|c|}
\hline & Site 1 & Site 2 & Site 3 \\
\hline Av. wall dimensions: $\mathrm{L}(\mathrm{m}) \times \mathrm{H}(\mathrm{m}) \times \mathrm{W}(\mathrm{cm})$ & $3.479 \times 0.624 \times 17.85$ & $1.766 \times 0.687 \times 19.6$ & $3.930 \times 0.888 \times 19.89$ \\
\hline Av. Unit dimensions- bricks: LxBxH (cm) & $17.85 \times 9.24 \times 4.54$ & $19.60 \times 9.55 \times 5.18$ & $19.89 \times 9.69 \times 4.91$ \\
\hline Type of sand & Medium & Medium & Medium \\
\hline COF - measured & 0.2805 & 0.2640 & 0.2640 \\
\hline Joint fullness factor F1 - Bed joint & 1.00 & 1.00 & 1.00 \\
\hline Joint fullness factor F2 - Chapparu & 1.00 & 1.00 & 1.00 \\
\hline Joint fullness factor F3 - H/c cross & 0.80 & 0.70 & 0.60 \\
\hline Joint fullness factor F4 - S/c cross & 0.80 & 0.80 & 0.70 \\
\hline Joint fullness factor F5 - Wall joint & 0.85 & 0.65 & 0.80 \\
\hline JFC (COB) - computed & 1.16296 & 1.159307 & 1.159307 \\
\hline JFC (RUM) - computed & 1.145309 & 1.142052 & 1.142052 \\
\hline Bed joint $(\mathrm{mm})$ & 11.30 & 16.89 & 19.22 \\
\hline Chapparu joint (mm) & 20.80 & 7.50 & 14.10 \\
\hline $\mathrm{H} / \mathrm{c}$ cross joint $(\mathrm{mm})$ & 13.98 & 14.15 & 17.28 \\
\hline $\mathrm{S} / \mathrm{c}$ cross joint $(\mathrm{mm})$ & 10.36 & 13.11 & 13.64 \\
\hline Wall joint $(\mathrm{mm})$ & 14.53 & 12.53 & 19.29 \\
\hline \multicolumn{4}{|l|}{ Theoretical mortar volumes (in cu.m.): } \\
\hline Course Based Method - COB & 0.1477 & 0.0890 & 0.3059 \\
\hline Representative Unit Method - RUM & 0.1506 & 0.0899 & 0.3099 \\
\hline Measured volume of mortar (cu.m.) & 0.1563 & 0.0858 & 0.3060 \\
\hline \multicolumn{4}{|l|}{ Variances: } \\
\hline Course Based Method - COB & $-5.50 \%$ & $+3.73 \%$ & $-0.03 \%$ \\
\hline Representative Unit Method - RUM & $-3.65 \%$ & $+4.78 \%$ & $+1.28 \%$ \\
\hline
\end{tabular}




\subsection{Mortar Volumes in Joints of Study Walls}

The average proportion of mortar volumes in the study walls (59 walls in 54 randomly selected sites) are shown in Fig. 5. These volumes have been computed using the $\mathrm{COB}$ method. Clearly, the bed joint accounts for a major portion of mortar used in brickwork (74\%) which is almost three times when compared with the volume of mortar in other joints. Average brick size and joint sizes are given as a footnote in Fig. 5. It appears that the high percentage of mortar may be due to the relatively smaller brick sizes and larger joint sizes when compared with standard size bricks. As such, the next section examines the impact of mortar volumes in standard size walls built using standard size bricks.

\subsection{Variation of Mortar Volumes in Joints of Walls with Standard Size Bricks}

Given the above observation, it is necessary to understand whether the proportion of mortar in walls with standard size bricks would be similar or different. Accordingly, mortar volumes were computed using the RUM method by assuming a joint size of $10 \mathrm{~mm}$, 'medium' type sand, a joint fullness \& compaction factor of 1 (i.e. completely filled with mortar). The factor for the bed joint was established by using the appropriate COF factor for medium type sand (from Table 2) and formula given in Table 5. The results are shown in Table 8.

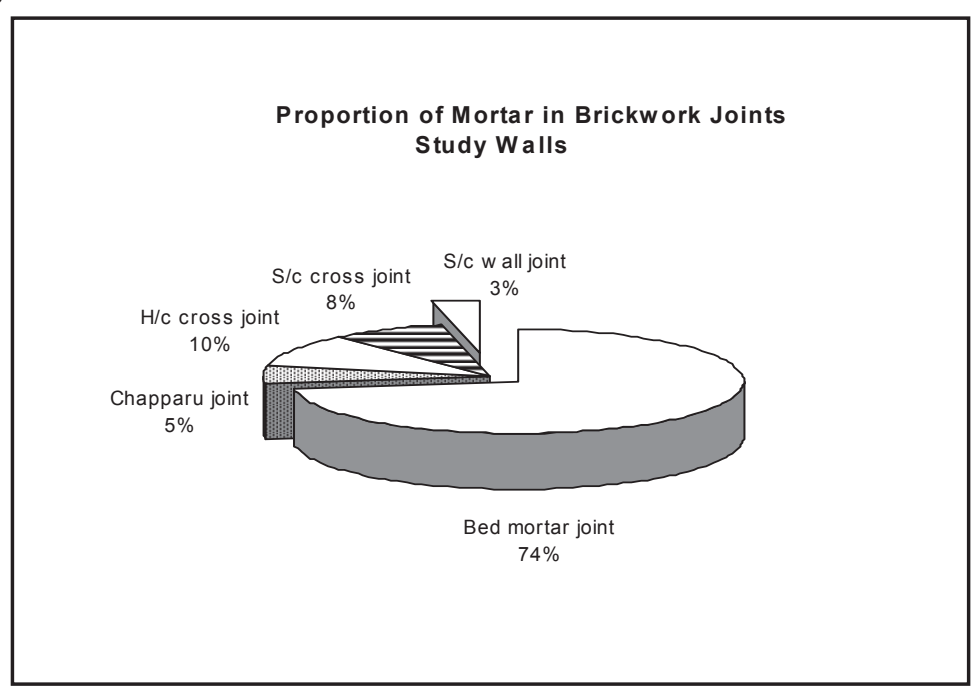

Figure 5- Proportion of mortar in brickwork joints for study walls $(\mathrm{S} / \mathrm{c}$ - Stretcher course; H/c - Header course; Av. brick size: 191 x 93.7 x 49.2; BMT=17.11;TH=14.67; TS=20.87)

Table 8 - Proportion of mortar in brickwork joints in walls using standard bricks sizes

\begin{tabular}{|c|c|c|c|c|c|c|}
\hline & $\begin{array}{c}\text { With bricks } \\
\text { used in this } \\
\text { study }\end{array}$ & $\begin{array}{c}\text { BS } \\
\text { Bricks }\end{array}$ & $\begin{array}{c}\text { SLS } \\
\text { Bricks }\end{array}$ & $\begin{array}{c}\text { Modu- } \\
\text { lar }\end{array}$ & BS & $\begin{array}{c}\text { Modu- } \\
\text { lar }\end{array}$ \\
\cline { 3 - 7 } Brickwork Joint & & $\begin{array}{c}215 \mathrm{x} \\
102.5 \mathrm{x}\end{array}$ & $\begin{array}{c}220 \mathrm{x} \\
105 \mathrm{x}\end{array}$ & $\begin{array}{c}190 \mathrm{x} \\
90 \mathrm{x}\end{array}$ & $\begin{array}{c}215 \mathrm{x} \\
102.5 \mathrm{x}\end{array}$ & $\begin{array}{c}190 \mathrm{x} \\
90 \mathrm{x} \\
\end{array}$ \\
& & 65 & 65 & 65 & 65 & 65 \\
\hline DATA:Chapparu & 12.50 & 0.00 & 0.00 & 0.00 & 0.00 & 0.00 \\
TH (mm) & 14.67 & 10.00 & 10.00 & 10.00 & 20.00 & 20.00 \\
TS (mm) & 20.87 & 10.00 & 10.00 & 10.00 & 20.00 & 20.00 \\
WJ (mm) & 16.08 & 10.00 & 10.00 & 10.00 & 10.00 & 10.00 \\
\hline Joint Fullness & Table 1 & 1.0 & 1.0 & 1.0 & 1.0 & 1.0 \\
\hline WT (mm) & 203.5 & 215.00 & 220.00 & 190.00 & 215.00 & 190.00 \\
\hline BED JOINT(\%) & 72.9 & 66.7 & 67.2 & 64.0 & 54.4 & 51.6 \\
\hline CHAPPARU(\%) & 5.3 & - & - & - & - & - \\
\hline H/C CROSS(\%) & 10.3 & 16.7 & 16.4 & 18.0 & 26.1 & 27.7 \\
\hline S/C CROSS(\%) & 8.2 & 8.3 & 8.2 & 9.0 & 13.0 & 13.8 \\
\hline S/C WALL(\%) & 3.3 & 8.3 & 8.2 & 9.0 & 6.5 & 6.9 \\
\hline
\end{tabular}

Note: All sizes are in millimetres; Abbreviations: WT - Wall thickness; WJ - Wall joint 
Interestingly, results in Table 8 show that proportion of mortar in the bed joint is the largest irrespective of the type of brick used with more than two thirds of the total volume of mortar (when bed joint size of $10 \mathrm{~mm}$ is used; see first three columns in Table 8). The dominance of the bed joint remains much the same even when the stretcher/header course cross joint size is increased to $20 \mathrm{~mm}$ (see last 2 columns, Table 8 ). Although the proportion is less than $2 / 3 \mathrm{rds}$, it can be shown that if the degree of joint fullness of perpend joints with respect to 'BS' and 'Modular' walls are reduced to 0.6 and 0.53 respectively, then the proportion of mortar in the bed joint can be increased to $2 / 3$ rds.

Shown in Fig. 6 is the variation of the proportion-of-bed-mortar with bed-mortarthickness for different standard sizes of bricks. A joint thickness of $10 \mathrm{~mm}$ and a joint fullness factor of 1 have been assumed. The RUM method has been used for computations.

An observation which can be made from this plot (Fig. 6) is that when 'standard' sizes of bricks are used with a bed mortar thickness of $20 \mathrm{~mm}$, the proportion of mortar in the bed joint increases to over $75 \%$. In practice this will be even higher as perpend joints would likely to be under filled (with Sri Lankan brickwork). As the bed joint increases further (up to about $30 \mathrm{~mm}$ ) it approaches 85\%, whilst for bricks used for study walls, it would be around $90 \%$.

Therefore, what may be concluded is that the bed-joint accounts for the largest portion of mortar in brickwork. As noted before, this proportion increases to about $75 \%$ when the bed mortar thickness is $20 \mathrm{~mm}$ and to about $85 \%$ when the joint size is $30 \mathrm{~mm}$ when standard size bricks and wall widths are used. However, if the perpend joint sizes are doubled from 10 to 20, with a small bed joint of $10 \mathrm{~mm}$, the proportion reduces to over $50 \%$ as shown in Table 8 (see last two columns). What is interesting is that significant changes in volume of mortar in joints can be achieved by manipulating joint sizes particularly the size of the bed joint.



Figure 6 - The proportion of bed mortar as a percentage of the total volume of mortar (Note: The curve labelled as 'study' uses average values for brick dimensions given in Fig. 5) 
It is also worth noting that such changes can be achieved by changing the degree of fullness of joints. With 'standard' sizes of bricks and standard size joints (i.e. hereinafter referred to as small joints), the impact of under filled cross/perpend joints would be marginal (see Table 7). If, however, perpend joints were to be increased to about $20 \mathrm{~mm}$ (hereinafter referred to as large joints), the impact of under filled joints could be substantial; to increase the proportion from about $50 \%$ to $67 \%$ (i.e. $2 / 3 \mathrm{rds}$ ), the degree of joint fullness has to be reduced to around 0.5-0.6.

\subsection{Variation of Mortar Volumes as a Proportion of Brick and Wall Volumes}

The focus of this section is to understand the distribution of mortar with respect to volume of mortar to bricks, and volume of mortar to wall, having examined the variation of volume of mortar with respect to brickwork joints and their sizes. As before, the RUM method was used for computation of volumes. The results are tabulated in Table 9.

The data in Table 9 shows that the proportion of mortar in a brick wall with standard size bricks is less than $25 \%$, and, when compared with the proportion of bricks, the proportion of mortar is generally less than $31 \%$. However, for the (59) study walls, the relevant percentages are significantly different as can be seen from Table 9 (i.e. $41 \%$, mainly due to the smaller brick sizes and larger bed joint sizes). Such a large volume of mortar in brickwork challenges the very notion of what 'brickwork' is. Interestingly, if the volume of mortar is greater than the volume of brick, it is pertinent to raise the question whether a different name would be more appropriate for such type of 'brickwork' (as there is more mortar than bricks). A possible classification is shown in Table 10.

\subsection{Understanding the variation of Brick to Mortar Ratio}

Having categorised 'brick-mortar' walls thus, and also having established that the bed joint accounts for the largest proportion of mortar of all types of wall joints, it is useful to examine the variation of the brick to mortar ratio with respect to brick size and bed joint size. It is also useful to reiterate at this stage that bed mortar accounts for a significantly large proportion of mortar of all joints as explained earlier.

Table 9 - Indicators of mortar consumption characteristics of walls

\begin{tabular}{|c|c|c|c|c|c|}
\hline & \multicolumn{2}{|c|}{$\begin{array}{l}\text { Study } \\
\text { Walls }\end{array}$} & $\begin{array}{c}\text { BS } \\
\text { bricks }\end{array}$ & $\begin{array}{c}\text { SLS } \\
\text { bricks }\end{array}$ & $\begin{array}{c}\text { Modular } \\
\text { bricks }\end{array}$ \\
\hline Characteristic & Av. & $\begin{array}{l}\text { Std. } \\
\text { Dev. }\end{array}$ & $\begin{array}{c}215 x \\
102.5 x \\
65\end{array}$ & $\begin{array}{c}220 x \\
105 x \\
65\end{array}$ & $\begin{array}{c}190 x \\
90 x \\
65\end{array}$ \\
\hline Vol. of mortar \% & 41.1 & 6.3 & 23.1 & 22.9 & 24.1 \\
\hline Vol. of mortar to bricks (\%) & 73.3 & 15.3 & 29.3 & 29.0 & 30.9 \\
\hline
\end{tabular}

Table 10 - A classification of walls involving brick and mortar

\begin{tabular}{|l|c|c|c|}
\hline \multicolumn{1}{|c|}{ Ratio } & \multicolumn{3}{|c|}{ Wall type } \\
& $\begin{array}{c}01 \\
\text { Brickwall }\end{array}$ & $\begin{array}{c}02 \\
\text { Brick-mortar wall }\end{array}$ & Mortar wall \\
\hline Vol. of bricks to mortar & $\geq 3.0$ & $3.0-1.0$ & $\leq 1.0$ \\
\hline Vol. of mortar to Bricks & $\leq 33.33 \%$ & $33.33 \%-100 \%$ & $\geq 100 \%$ \\
\hline Vol. of mortar to wall & $\leq 25 \%$ & $25 \%-50 \%$ & $\geq 50 \%$ \\
\hline
\end{tabular}


Three cases are considered herein as shown in Table 10. Mortar volumes have been computed by the use of the RUM method with respect to medium type sand. Case 1 and 2 refer to a wall thickness of $220 \mathrm{~mm}$ whilst Case 3 refers to a reduced size of $200 \mathrm{~mm}$ (a common wall width used in the Sri Lankan construction industry). The sizes of cross joints used in Case 1 are 'standard' values whereas in Cases 2 and 3, they are the averages of study walls.

It can be seen from Table 10that this ratio is very sensitive to small variations in the thickness of the bed joint at small values in relation to SLS and BS bricks; its sensitivity increases remarkably with larger sizes of bricks. (See Fig. 7.) In addition, it is also sensitive to small variations in cross joints at low values of bed joint (compare Case 1 and 2, middle column data).

Therefore, the implication is that when bricks are laid with small joints (i.e. approximately < $15 \mathrm{~mm}$ ) greater care needs to be taken to control the 'bricks to mortar' ratio. In other words, high workmanship and smaller tolerances of bricks are pre-requisites for building walls with smaller joint sizes if this ratio is to be maintained.

The variation of the ratio referred to above, i.e. bricks to mortar, with respect to different sizes of bed joints for different sizes of brick sizes are shown in Fig.7. The inclination of the graph for BS and SLS bricks for changes in bed joint thicknesses up to $20 \mathrm{~mm}$ is significant reconfirming the sensitivity of this ratio for larger sizes (i.e. of standard sized bricks).

This discussion is useful to develop a strategymap for either maximising or minimising the bricks-to-mortar ratio which is shown in Table 12.

\section{Significance of the Findings}

In Sri Lanka, most walls built using bricks are plastered due to various reasons [8] which make it possible to vary joint sizes as so long as wall widths are maintained. When single brick thick walls are built in English bond, neither the size of the bed joint nor the perpend joints excluding the wall joint has an impact on the wall width. Moreover, openings for doors and windows can be accommodated simply by varying the size of the bed joints in a number of different ways. Thus, it must be emphasised that a desirable bricks to mortar ratio can be adopted by varying these joint sizes to reduce costs [1] and/or increase output [4]. As such, what needs to be described herein is how this can be achieved (taking a macro perspective) given that time, cost, and productivity issues have all been described in other papers published by the author. It is in this regard that the strategy-map shown in Table 12 becomes useful.

Consider, for example, that cost density of bricks (cost per unit volume including materials and labour) is higher than mortar (i.e. cost per unit volume). Clearly, in such a situation, costs could be reduced by using smaller bricks and larger joints; greater the polarity, greater is the opportunity for reducing costs [2]. If the reverse is the case, i.e., cost density of mortar is greater than bricks, it makes sense to use larger bricks and smaller joints.

Table 11- The variation of 'volume of bricks to volume of mortar' ratio with bed mortar thickness

\begin{tabular}{|c|c|c|c|c|c|c|c|c|c|}
\hline & \multicolumn{3}{|c|}{ Case 1 } & \multicolumn{3}{c|}{ Case 2 } & \multicolumn{3}{c|}{ Case 3 } \\
\hline & \multicolumn{1}{|c|}{ WT=220; TH=10; TS=10 } & WT=220; TH=14.67; TS=20.87 & \multicolumn{2}{c|}{ WT=200; TH=14.67; TS=20.87 } \\
\hline $\begin{array}{c}\text { BMT } \\
(\mathrm{mm})\end{array}$ & SLS & BS & Lo/Sm & SLS & BS & Lo/Sm & SLS & BS & Lo/Sm \\
\hline 05 & 11.88 & 8.95 & 2.91 & 4.07 & 3.59 & 1.81 & - & - & 2.41 \\
\hline 10 & 5.79 & 4.94 & 2.06 & 2.88 & 2.61 & 1.39 & - & - & 1.77 \\
\hline 15 & 3.83 & 3.41 & 1.59 & 2.23 & 2.05 & 1.13 & - & - & 1.40 \\
\hline 17.11 & 3.35 & 3.02 & 1.45 & 2.03 & 1.88 & 1.05 & - & - & 1.28 \\
\hline 20 & 2.86 & 2.60 & 1.30 & 1.81 & 1.69 & 0.95 & - & - & 1.15 \\
\hline 25 & 2.28 & 2.11 & 1.09 & 1.53 & 1.43 & 0.82 & - & - & 0.98 \\
\hline 30 & 1.90 & 1.77 & 0.95 & 1.32 & 1.25 & 0.72 & - & - & 0.86 \\
\hline
\end{tabular}

BMT - Bed mortar thickness; WT - Wall thickness; TH,TS - Header course/Stretcher course joint sizes; SLS - Sri Lanka Standard brick; BS - British Standard brick; Lo/Sm- Local small brick: 180 ×90 x 47.5 mm 
Table 12 - Strategy-map for selecting brick-to-mortar ratios (\#)

\begin{tabular}{|l|c|l|c|c|c|c|c|}
\hline & \multicolumn{5}{|c|}{ Bricks-to-Mortar ratio } \\
\hline & $\mathbf{1 0 - 6}$ & $\mathbf{4}$ & $\begin{array}{c}\mathbf{3} \\
\text { Case 1 }\end{array}$ & $\begin{array}{c}3 \\
\text { Case 2 }\end{array}$ & $\begin{array}{c}\mathbf{2} \\
\text { Case 2 }\end{array}$ & $<2$ to 1 & $<\mathbf{1}$ \\
\hline Brick size & LARGE* & LARGE* & LARGE* & Small & Small & Small & Small \\
\hline Joint size & small & Medium & Large & Large & $\begin{array}{c}\text { mediu } \\
\text { m }\end{array}$ & Large & Large \\
\hline $\begin{array}{l}\text { Indicative bed joint } \\
\text { (mm) }\end{array}$ & $5-10$ & 15 & 20 & 20 & 10 & $10-25$ & 25 \\
\hline $\begin{array}{l}\text { Sensitivity to changes } \\
\text { in bed joint size }\end{array}$ & HIGH & Moderate & Low & Low & Low & Low & Low \\
\hline $\begin{array}{l}\text { Degree of control } \\
\text { reqd. to reach } \\
\text { desirable goals (cost) }\end{array}$ & HIGH & Moderate & Low & HIGH & Low & Low & Low \\
\hline $\begin{array}{l}\text { Type of wall } \\
\text { Brick- }\end{array}$ & Brick- & $\begin{array}{c}\text { Brick- } \\
\text { wortar } \\
\text { wall }\end{array}$ & $\begin{array}{c}\text { Brick- } \\
\text { morta } \\
\text { r wall }\end{array}$ & $\begin{array}{c}\text { Brick- } \\
\text { mortar } \\
\text { wall }\end{array}$ & $\begin{array}{c}\text { Brick- } \\
\text { mortar } \\
\text { wall }\end{array}$ & $\begin{array}{c}\text { Mortar } \\
\text {-wall }\end{array}$ \\
\hline
\end{tabular}

*BS/SLS bricks; \# - Also see Fig. 7

Such changes can be achieved by varying joint sizes particularly the bed joint as it accounts for over two thirds of the mortar in brickwork joints even when BS or SLS bricks are used with the standard joint size of $10 \mathrm{~mm}$ (as shown before). However, when doing so, it is important to keep in mind that with larger bricks to mortar ratios, as the ratio is quite sensitive to changes in smaller bed joints, there is a need for a higher standard of workmanship as mentioned before. In contrast, with smaller bricks to mortar ratios, given that it is less sensitive to small changes in bed joint size, workmanship issues do not have a significant impact on the ratio. In other words, when cost density of mortar is less than bricks, it would generally be easier to manage the impact on costs particularly with 'brick- mortar' (type 2) and 'mortar-walls' (type 3) noted in Table 10.

What is also interesting to note is that the understanding so gained provides a basis for specifying a particular type of wall using the rules given in Table 13.

It should be pointed out that no consideration is given for strength of walls as when walls are used as partition walls or when they are lightly loaded. However, if the walls are designed as loadbearing walls (particularly for carrying large loads), then there is a need to exercise more care and judgement when using the above strategy maps.

Table 13 - Strategy map for specifying walls for cost minimisation (Non-loadbearing and lightly loaded walls)

\begin{tabular}{|c|c|c|c|c|}
\hline $\begin{array}{c}\text { Cost polarity } \\
\text { (Cost density of } \\
\text { bricks to mortar) }\end{array}$ & \multicolumn{2}{|c|}{$\begin{array}{c}\text { For cost minimisation } \\
\text { specify: }\end{array}$} & $\begin{array}{c}\text { Workmanship required } \\
\text { for controlling joint sizes }\end{array}$ & $\begin{array}{c}\text { Potential for cost } \\
\text { minimisation }\end{array}$ \\
\hline & Type & Description & & High \\
& 1 & $\begin{array}{c}\text { Brick wall } \\
\text { Brick-mortar wall }\end{array}$ & $\begin{array}{c}\text { High } \\
\text { Moderate }\end{array}$ & Negligible \\
& 2 & 1 & Any type & $\begin{array}{c}\text { High } \\
\text { Moderate } \\
\text { Low }\end{array}$ \\
\hline$>1$ & 2 & 3 & Mow & High \\
& 2 & Brick-mortar wall & Moderate & Moderate \\
\hline
\end{tabular}




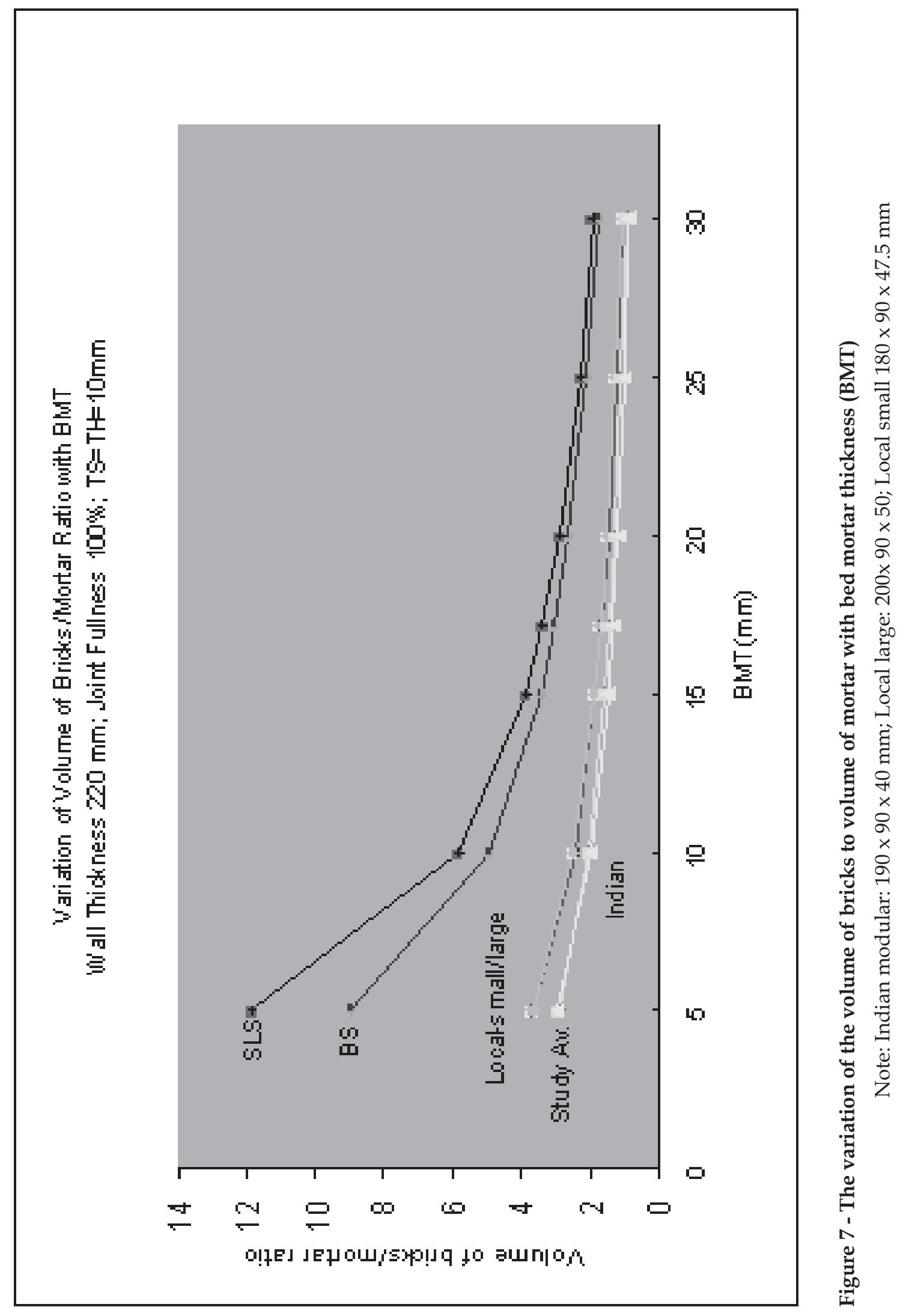




\section{Conclusions and Recommendations}

One of the main intentions of this study was to understand the impact of brick and joint sizes on 'mortar consumption characteristics' and thereby develop a framework to propose how bricks and mortar could be used in a chaotic environment.

The study recommends classifying walls built with bricks and mortar into three types, namely, brick-walls, brick-mortar walls, and mortar walls based on 'bricks to mortar' ratios.

In order to specify a wall type, the concept of 'cost polarity' should be used firstly followed by other criteria given in Table 13, namely, workmanship, and potential for cost saving.

In order to minimise costs, a suitable bricks to mortar ratio needs to be selected for a given width of wall for which purpose, information given in Table 12 should be used for selecting suitable brick and joint sizes for single brick thick walls carrying light loads. All the bed joint sizes given in Table 13 are buildable. For more in-depth information on the build ability of the bed joint, reader is referred to Abeysekera and Thorpe's publication on this topic [9]. Costs could be minimised by adjusting not only the size of the bed joint but also other joints including joint fullness [1], [4].

It must be pointed out that further studies may need to be undertaken to study the impact of changes in joint sizes with respect to strength when bricks are to be used in loadbearing construction.

Nevertheless, the framework proposed above provides a fresh perspective on how to manage 'chaotic- brickwork', particularly in the context of Sri Lankan brickwork. The potential for cost saving is enormous only if non-standard joint sizes are used. Indeed, the challenge is to use a chaotic environment to bring a new order!

\section{References}

1. Abeysekera, V., \& Thorpe, A., "Optimising Brickwork Costs in a Complex and Chaotic Environment", Engineer: Journal of the Institution of Engineers, Sri Lanka, Volume 1 - Part B, Transactions, 94-110, 1997.

2. Abeysekera, V. and Abeysekera, A., Laying the Foundation for a Theory of Brickwork, First Symposium, Towards the Foundation of Theory for the Built Environment, Research Institute for the
Built and Human Environment, Salford University, UK, 18-19 June, 2007.

3. Abeysekera, V., \& Thorpe, A., "A New Technology to bring 'Order' out of 'Chaos'? The Case of Brickwork in Sri Lanka and Bangladesh",International Conference on Construction Industry Development, eds., National University of Singapore in association with CIDB (Singapore), ACI (US), ACI (Australia), ACI (UK), Singapore, December, 179-189, 1997.

4. Abeysekera, V., "Output Characteristics of Chapparu Brickwork", Engineer: Journal of the Institution of Engineers, Sri Lanka, 43 (4). pp. 5774, 2010.

5. Hendry, A.W., Workmanship Factors in Brickwork Strength, BDA Technical Note, Vol 1, No. 6, Nov. 1972.

6. Chandrakeerthi, S.R. de S., Local Bricklaying Practices, Engineer: Journal of the Institution of Engineers, Sri Lanka, Transactions, p. 90-102, 1987.

7. Chandrakeerthi, S.R. de S., Local Bricklaying Practices, Engineer: Journal of the Institution of Engineers, Sri Lanka, Transactions, p. 94, 1987.

8. Abeysekera, W.V.K.M., A Strategy for Managing Brickwork in Sri Lanka, PhD Thesis, Loughborough University, U.K., p. 7, 1997.

9. Abeysekera, V., and Thorpe, A., Bricklayers' Perspectives on the Buildability of the bedjoint and the Threat to Standardisation vis-avis Cost Optimisation. Challenges and Opportunities in Management and Technology, 1st International Conference on Construction in the 21st Century I. Ahmad, S. Ahmed, and S. Azhar, eds., Florida International University, Miami, USA, 25-25 April, 33-40, 2002. 